\title{
High expression of HEF1 predicts a poorer prognosis of hepatocellular carcinoma: A retrospective study
}

\author{
MEI LI* , SHUMEI YAN*, MUYAN CAI, JIABIN LU, MEIFANG ZHANG, PING YANG and RONGZHEN LUO \\ Sun Yat-sen University Cancer Center, State Key Laboratory of Oncology in South China, \\ Collaborative Innovation Center for Cancer Medicine, Guangzhou, Guangdong 510060, P.R. China
}

Received July 13, 2015; Accepted December 8, 2015

DOI: $10.3892 / \operatorname{mco} .2015 .707$

\begin{abstract}
Human enhancer of filamentation 1 (HEF1), a scaffold protein, is highly expressed in a variety of cancer types and is involved cancer cell growth, migration and invasion. The prognostic value of HEF1 in hepatocellular carcinoma (HCC) remains to be elucidated. The aim of the present study was to assess the association between the expression of HEF1, the clinical/pathological parameters and survival in HCC. In the present study, immunohistochemistry was performed to investigate the protein expression of HEF1 in 123 hepatocellular carcinoma tissues and their adjacent normal liver tissues. Spearman's rank correlation, Kaplan-Meier plots and Cox regression model were used to analyze the data. Overexpression of HEF1 protein was observed in HCC tissue when compared with their adjacent non-malignant liver tissue. High expression of HEF1 correlated with higher advanced tumor, node, metastasis (TNM) stage and vascular invasion $(\mathrm{P}<0.05)$. In univariate and multivariate analysis, the expression of HEF1 was identified as an independent prognostic factor in the 123 patients with HCC. In subgroup analysis, high expression of HEF1 correlated with a poorer prognosis in advanced (TNM III+IV) stages $(\mathrm{P}<0.05)$. These findings demonstrated the potential value of detecting the expression of HEF1 by immunohistochemistry as a prognostic biomarker and therapeutic target for patients with HCC.
\end{abstract}

\section{Introduction}

Hepatocellular carcinoma (HCC) is the fifth most common cancer type, ranking as the third leading cause of cancer-associated mortality due to its high invasive and metastatic potential (1). The morbidity and mortality of HCC is markedly higher in the China and Asian Pacific region as a result of the

Correspondence to: Dr Rongzhen Luo, Sun Yat-sen University Cancer Center, State Key Laboratory of Oncology in South China, Collaborative Innovation Center for Cancer Medicine, 651 Dongfeng Road East, Guangzhou, Guangdong 510060, P.R. China

E-mail: rongzhenluo@163.com

*Contributed equally

Key words: HEF1, hepatocellular carcinoma, prognosis prevalence of hepatitis B and C viral infections (2). Due to the lack of an early diagnostic system, the majority of patients with HCC are diagnosed at advance stages. Recurrence and metastasis are the leading causes of mortality in patients with HCC (3). Therefore, identifying novel diagnostic and therapeutic targets of $\mathrm{HCC}$ is urgently required.

Human enhancer of filamentation 1 (HEF1), also termed neural precursor cell-expressed developmentally downregulated 9 or Crk-associated substrate lymphocyte type, was first identified in neuronal precursor cells by Kumar et al (4) in 1992. HEF1 is located on human chromosome 6p25-24 and its translational product contains 843 amino acids. According to previous studies, HEF1 is a scaffold protein and is involved in a variety of cellular functions and behaviors, including cell adhesion, migration, invasion, apoptosis and cell cycle (5-8). Previous studies indicate that HEF1 is important in the development of numerous cancer types, particularly in the metastatic process (9-15). In prostate cancer, HEF1 promotes the epithelial mesenchymal transition and bone invasion under the regulation of microRNA-145 (16). In pancreatic carcinoma, patients with a high expression of HEF1 exhibited a significantly poorer prognosis compared with those with low expression of HEF1 (12).

However, the role of HEF1 and its clinical significance in HCC remain to be elucidated. The aim of the present study was to evaluate the expression of HEF1 in HCC and determine its clinical significance. Immunohistochemistry (IHC) was performed to examine the protein expression levels of HEF1 in 123 HCC tissues and adjacent normal liver tissues. Correlation between the expression of HEF1, and the clinicopathological characteristics and patient survival were analyzed.

\section{Materials and methods}

Patient information. The present study was approved by the medical ethics committee of Sun Yat-sen University Cancer Center (Guangdong, China). Written informed consent was obtained from all patients involved. In the present study, all paraffin-embedded pathological specimens from 123 patients [107 (87.0\%) men and $16(13.0 \%)$ women; mean age, 47.7 years] with HCC were collected from the archives of the Department of Pathology, Sun Yat-Sen University Cancer Center. Patients enrolled in the present study were diagnosed with HCC between July 2005 and May 2008, undergoing primary and curative resection for tumor without preoperative anticancer treatment. 
The average follow-up time was 26.79 months (median, 28.0; range, 1.0-61 months). Clinicopathological characteristics of these patients, including age, sex, hepatitis history, serum $\alpha$-fetoprotein (AFP), liver cirrhosis, tumor number, size, differentiation, vascular invasion, relapse and tumor, node metastasis (TNM) stage are summarized in Table I. Tumor differentiation was determined, according to the criteria proposed by Edmonson and Steiner (17). The histological grade and clinical stage of the tumors were defined, according to the International Union Against Cancer TNM classification system (18).

Tissue microarray (TMA) construction. TMA was constructed, as previously described (19). Briefly, triplicates of the core tissue biopsies ( $0.6 \mathrm{~mm}$ diameter) were obtained from the representative tumor area and adjacent non-malignant liver tissue of each donor tissue block, which was rearranged in recipient paraffin blocks (tissue array blocks) using a tissue arraying instrument (Beecher Instruments, Silver Spring, MD, USA).

IHC.IHC was performed to assess the altered protein expression in $123 \mathrm{HCC}$ tissues. Briefly, TMA slides were heated at $60^{\circ} \mathrm{C}$ for $2 \mathrm{~h}$ prior to deparaffinization with xylene (Guangzhou Chemical Reagent Factory, Guangzhou, China) and rehydrated in graded alcohol. The tissue sections were boiled in antigen retrieval buffer for $15 \mathrm{~min}$ in a microwave oven to retrieve antigen, followed by incubation with $3 \%$ hydrogen peroxide in methanol to quench endogenous peroxidase activity. Following this, $1 \%$ bovine serum albumin (Sigma-Aldrich, St. Louis, MO, USA) was used to block non-specific binding. Subsequently, the tissue sections were incubated with rabbit anti-human anti -HEF1 (cat. no. ab18056; $10 \mu \mathrm{g} / \mathrm{ml}$; Abcam, Burlingame, CA, USA) at $4^{\circ} \mathrm{C}$ overnight. Replacement of the primary antibody with phosphate buffered saline was performed as a negative control. Following incubation with rabbit anti-mouse peroxidase/DAB-conjugated secondary antibody (Envision; Dako, Glostrup, Denmark) for $30 \mathrm{~min}$ at $37^{\circ} \mathrm{C}$, the slides were incubated with 3,3-diaminobenzidine solution at room temperature for visualization. The tissue samples were subsequently dehydrated and mounted using neutral balsam (Sigma-Aldrich).

IHC evaluation. The immunoreactivity score (IRS) for HEF1 expression were determined by two independent pathologists, in a blinded manner (Fig. 1). The staining results were scored based on the following criteria: i) Percentage of positive tumor cells in the tumor tissue: $0(0 \%), 1(1-10 \%), 2(11-50 \%), 3(51-75 \%)$ and $4(76-100 \%)$; ii) signal intensity: 0 (no signal), 1 (weak), 2 (moderate) and 3 (marked). The IRS was calculated by multiplying the score for the percentage of positive cells by the intensity score (range, 0-12). The specimens were rescored if the difference between the two pathologists was $>3$. The definition of low and high expression levels of HEF1 was determined by the median of the IRS results. Representative figures are shown in Fig. 1.

Statistical analysis. Statistical analysis was performed using SPSS 17.0 software (SPSS, Inc., Chicago, IL, USA). The correlation between the expression of HEF1 and clinicopathological variables were assessed using Pearson's $\chi^{2}$ test. The overall survival (OS) and disease free survival (DFS) were assessed by Kaplan-Meier curve. The Cox regression model was used for multivariate survival analysis. A two-sided $\mathrm{P}<0.05$ was considered to indicate a statistically significant difference.

\section{Results}

Expression of HEFl in HCC and adjacent non-malignant liver tissues by IHC. The clinicopathological characteristics of the 123 patients are listed in Table I. Immunostaining of HEF1 in HCC and normal hepatocyte tissues were indicated as brown yellow granules in the cytoplasm (Fig. 1). The expression of HEF1 was divided into two subgroups: Low and high HEF1 expression, as defined by IHC evaluation. High expression of HEF1 was detected in 38.2\% (47/123) adjacent non-malignant normal tissues, whereas high expression of HEF1 was detected in 51.2\% (63/123) of HCC cases. Paired sample tests revealed that the positive rate of HEF1 expression between normal and HCC cases was statistically significant (Table II; $\mathrm{P}<0.05$ ).

Association between HEF1 expression and clinicopathological variables. The association between immunohistochemical HEF1 expression in HCC tissues and various clinicopathological features of patients with HCC were analyzed by Pearson's $\chi^{2}$ test and are listed in Table I. The expression of HEF1 correlated closely with TNM stage $(\mathrm{P}=0.019)$ and vascular invasion status $(\mathrm{P}=0.008)$. However, no statistical correlations were observed between HEF1 expression and age, sex, AFP levels, liver cirrhosis, tumor size, tumor multiplicity, differentiation and cancer relapse $(\mathrm{P}=0.647,0.712,0.423,0.443,0.103,0.077$, 0.439 and 0.083 respectively).

HEF1 expression and survival. All 123 hepatocellular carcinoma patients underwent 5 year follow-ups. The OS was defined as the duration between the date of initial surgery and mortality, or the most recent follow-up. The 5 year OS indicated by the Kaplan-Meier survival curve of low and high HEF1 expression is shown in Fig. 2. Patients with low expression of HEF1 had a significantly longer OS and DFS when compared with the patients exhibiting high expression of HEF1 $(\mathrm{P}=0.001)$. The 5 year survival rates for low and high HEF1 expression patients were 68.8 and $38.9 \%$, respectively. The mean survival duration of patients with low expression levels of HEF1 was 49.2 months, whereas the mean survival time of patients with high expression levels of HEF1 was 33.4 months.

In addition, the present study also examined the prognostic value of immunohistochemical HEF1 expression in different subgroups of patients with HCC, according to the classical TNM stage classification. Significant correlations between high expression of HEF1, and shorter OS and DFS time were observed in advanced TNM (stage III+IV) subgroups $(\mathrm{P}<0.05$; Fig. 2), which suggested that HEF1 expression is an effective prognostic marker for HCC patients in both early and advanced stages.

Furthermore, univariate and multivariate analyses were used to assess the prognostic value of HEF1 expression in HCC. The results revealed that the following variables correlated significantly with OS: AFP levels, tumor size, tumor multiplicity, TNM stage, vascular invasion, cancer relapse and 
Table I. Correlation between HEF1 expression and the clinicopathological variables of primary hepatocellular carcinoma cases.

\begin{tabular}{|c|c|c|c|c|}
\hline \multirow[b]{2}{*}{ Variable } & \multirow[b]{2}{*}{ No. cases $(n=123)$} & \multicolumn{2}{|c|}{ HEF1 expression, $\mathrm{n}(\%)$} & \multirow[b]{2}{*}{ P-value ${ }^{a}$} \\
\hline & & Low & High & \\
\hline Age (years) ${ }^{b}$ & & & & 0.647 \\
\hline$\leq 48.3$ & 60 & $28(46.7)$ & $32(53.3)$ & \\
\hline$>48.3$ & 63 & $32(50.8)$ & $31(49.2)$ & \\
\hline Gender & & & & 0.712 \\
\hline Male & 106 & $51(48.1)$ & $55(51.9)$ & \\
\hline Female & 17 & $9(52.9)$ & $8(47.1)$ & \\
\hline $\operatorname{AFP}(\mathrm{ng} / \mathrm{ml})$ & & & & 0.423 \\
\hline$\leq 20$ & 59 & $31(52.5)$ & 28 (47.5) & \\
\hline$>20$ & 64 & $29(45.3)$ & $35(54.7)$ & \\
\hline Liver cirrhosis & & & & 0.443 \\
\hline Yes & 86 & $40(46.5)$ & $46(53.5)$ & \\
\hline No & 37 & $20(54.1)$ & $17(45.9)$ & \\
\hline Tumor size (cm) & & & & 0.103 \\
\hline$\leq 5$ & 75 & $41(54.7)$ & $34(45.3)$ & \\
\hline$>5$ & 48 & $19(39.6)$ & $29(60.4)$ & \\
\hline Tumor multiplicity & & & & 0.077 \\
\hline Single & 85 & $46(54.1)$ & $39(45.9)$ & \\
\hline Multiple & 38 & $14(36.8)$ & $24(63.2)$ & \\
\hline Differentiation & & & & 0.439 \\
\hline Well & 15 & $8(53.3)$ & $7(46.7)$ & \\
\hline Moderate & 71 & $36(50.7)$ & $35(49.3)$ & \\
\hline Poor & 31 & $15(48.4)$ & $16(51.6)$ & \\
\hline Undifferentiated & 6 & $1(16.7)$ & $5(83.3)$ & \\
\hline Stage & & & & $0.019^{\mathrm{c}}$ \\
\hline I & 10 & $8(80.0)$ & $2(20.0)$ & \\
\hline II & 54 & $29(53.7)$ & $25(46.3)$ & \\
\hline III & 50 & $22(44.0)$ & $28(56.0)$ & \\
\hline IV & 9 & $1(11.1)$ & $8(88.9)$ & \\
\hline Vascular invasion & & & & $0.008^{\mathrm{c}}$ \\
\hline Yes & 58 & $21(36.2)$ & $37(63.8)$ & \\
\hline No & 65 & $39(60.0)$ & $26(40.0)$ & \\
\hline Relapse & & & & 0.083 \\
\hline Yes & 42 & $16(38.1)$ & $26(61.9)$ & \\
\hline No & 81 & $44(54.3)$ & $14(45.7)$ & \\
\hline
\end{tabular}

${ }^{\mathrm{a}} \chi^{2}$ test; ${ }^{\mathrm{b}}$ Mean age; ${ }^{\mathrm{c}} \mathrm{P}<0.05$, statistically significant. AFP, $\alpha$-fetoprotein.

HEF1 expression (Table III). Multivariate analysis indicated that only HEF1 expression, serum AFP level and TNM stages were independent factors, which affected the OS ( $\mathrm{P}<0.05$; Table III).

\section{Discussion}

HEF1, also termed neural precursor cell-expressed developmentally downregulated 9 or Crk-associated substrate lymphocyte type, is identified as a member of the Crk-associated substrate protein family (4). Although no enzymatic domains have been determined in the amino acid sequence of HEF1, its cytoplasmic location and numerous tyrosine residues for phosphorylation by tyrosine kinases enable it to function as a scaffold protein for intracellular signal transduction (20). Previous studies indicate that HEF1 is involved in a diversity of cellular functions and behaviors, including cell adhesion, migration, invasion, apoptosis and cell cycle (5-8).

In particular, overexpression of HEF1 and its association with unfavorable prognosis have been revealed in diverse cancer types, including melanoma, bladder cancer, ovarian cancer, gastric cancer and colorectal cancer (11,21-24). In addition, Cox analysis and the Kaplan-Meier method revealed 

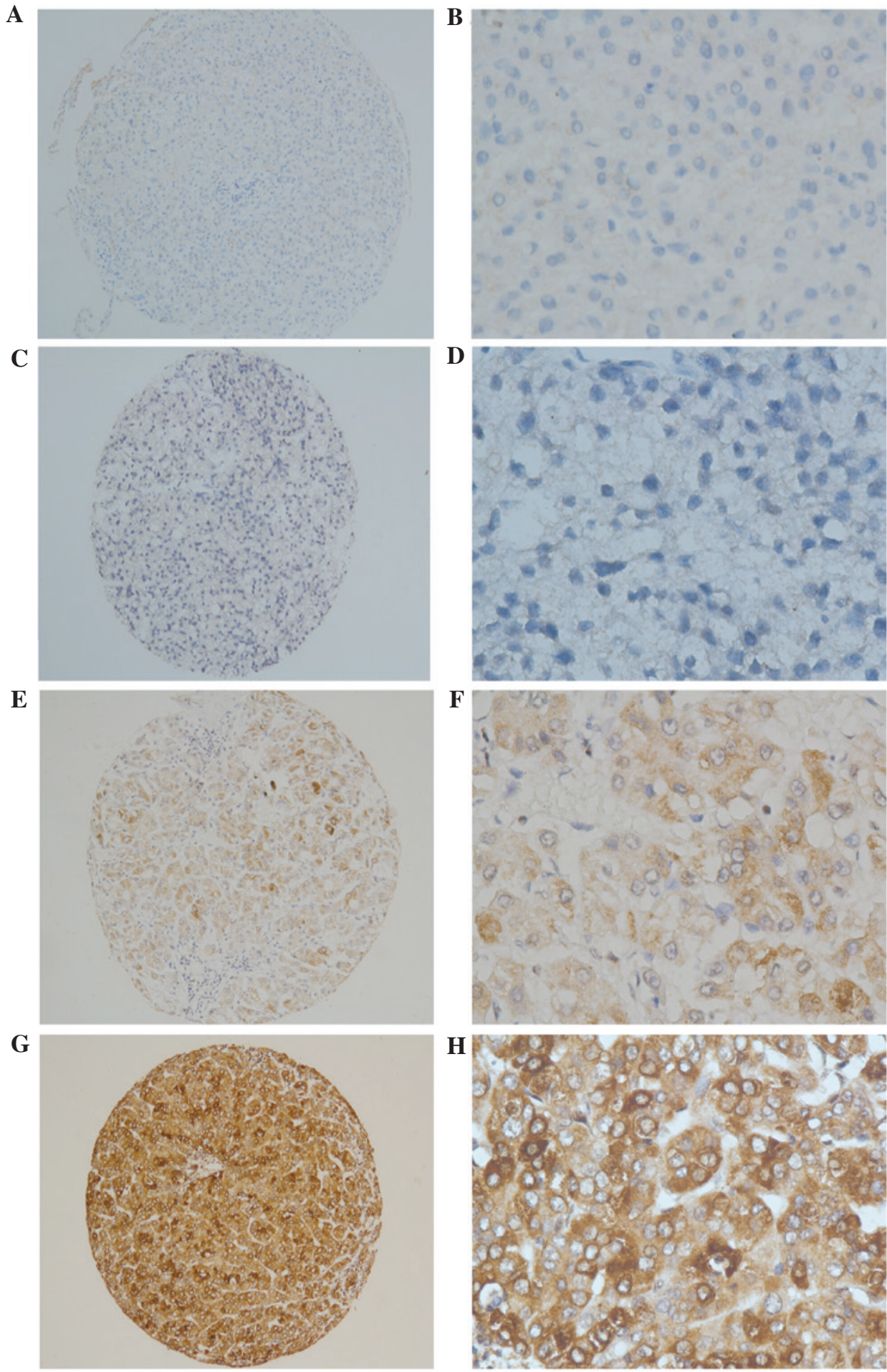

Figure 1. Expression levels of HEF1 detected by immunohistochemical staining. (A and B) Negative protein expression of HEF1 exhibited in a normal non-malignant liver case. (C and D) Negative protein expression of HEF1 in an HCC case. (E and F) Low and (G and H) high expression levels of HEF1 in an HCC case (magnification, A, C, E and G: x100, and B, D, F and H: x400). HCC, hepatocellular carcinoma.

that HEF1 expression is an independent prognostic factor in these cancer types and may serve as a predictive biomarker for these patients. The present study of HEF1 in HCC is consistent with these findings. A significantly upregulated HEF1 expression was observed in HCC tissues compared with in normal non-malignant liver tissues, as shown in Table II. Correlation analysis between the expression of HEF1 and the clinicopathological parameters of patients with HCC revealed that HEF1 overexpression was associated with advanced TNM stage and vascular invasion, indicating that HEF1 expression may be responsible for tumor progression and metastasis in HCC. Further analysis revealed that HEF1 expression is an independent prognostic factor for patients with HCC, suggesting its potential to serve as an effective biomarker for prognosis prediction and therapeutic target.

In terms of the mechanisms by which HEF1 regulates cancer cell growth and metastasis, certain early studies showed that HEF1 level is decreased in metastatic samples when compared 
Table II. Comparison of HEF1 expression in 123 paired HCC and adjacent non-malignant normal tissues.

\begin{tabular}{|c|c|c|c|c|}
\hline \multirow[b]{2}{*}{ Tissue } & \multirow[b]{2}{*}{ Number } & \multicolumn{2}{|c|}{ HEF1 expression, $n$} & \multirow[b]{2}{*}{$\%$ high expression } \\
\hline & & Low & High & \\
\hline Normal $^{\mathrm{a}}$ & 123 & 76 & 47 & 38.2 \\
\hline $\mathrm{HCC}^{\mathrm{a}}$ & 123 & 60 & 63 & 51.2 \\
\hline
\end{tabular}

${ }^{\mathrm{a}} \mathrm{P}=0.023(\mathrm{P}<0.05$, statistically significant $)$. HCC, hepatocellular carcinoma.

Table III. Univariate and multivariate analysis of different prognostic factors in 123 patients with hepatocellular carcinoma using Cox Proportional Hazards Regression.

\begin{tabular}{|c|c|c|c|c|c|}
\hline \multirow[b]{2}{*}{ Variable } & \multirow[b]{2}{*}{ All cases } & \multicolumn{2}{|c|}{ Univariate analysis } & \multicolumn{2}{|c|}{ Multivariate analysis } \\
\hline & & $\mathrm{HR}(95 \% \mathrm{CI})$ & P-value & HR $(95 \% \mathrm{CI})$ & P-value \\
\hline Age (years) ${ }^{\mathrm{a}}$ & & & 0.720 & & \\
\hline$\leq 48.3$ & 60 & 1.0 & & & \\
\hline$>48.3$ & 63 & $1.111(0.626-1.971)$ & & & \\
\hline Gender & & & 0.519 & & \\
\hline Male & 106 & $1.327(0.562-3.133)$ & & & \\
\hline Female & 17 & 1.0 & & & \\
\hline AFP (ng/ml) & & & $<0.001$ & & 0.005 \\
\hline$\leq 20$ & 59 & 1.0 & & 1.0 & \\
\hline$>20$ & 64 & $3.363(1.790-6.319)$ & & $2.694(1.359-5.337)$ & \\
\hline Liver cirrhosis & & & 0.754 & & \\
\hline Yes & 86 & $1.106(0.590-2.071)$ & & & \\
\hline No & 37 & 1.0 & & & \\
\hline Tumor size $(\mathrm{cm})$ & & & $<0.001$ & & 0.956 \\
\hline$\leq 5$ & 75 & 1.0 & & 1.0 & \\
\hline$>5$ & 48 & $2.911(1.619-5.234)$ & & $0.981(0.492-1.956)$ & \\
\hline Tumor multiplicity & & & $<0.001$ & & 0.369 \\
\hline Single & 85 & 1.0 & & 1.0 & \\
\hline Multiple & 38 & $3.749(2.099-6.696)$ & & $1.347(0.703-2.581)$ & \\
\hline Differentiation & & & 0.103 & & \\
\hline Well-moderate & 86 & 1.0 & & & \\
\hline Poor-undifferentiated & 37 & $1.642(0.905-2.980)$ & & & \\
\hline Stage & & & $<0.001$ & & 0.007 \\
\hline I-II & 64 & 1.0 & & 1.0 & \\
\hline III-IV & 59 & $25.241(7.812-81.551)$ & & $11.406(1.933-67.300)$ & \\
\hline Vascular invasion & & & $<0.001$ & & 0.314 \\
\hline Yes & 58 & $18.394(6.554-51.619)$ & & $2.172(0.479-9.839)$ & \\
\hline No & 65 & 1.0 & & 1.0 & \\
\hline Relapse & & & $<0.001$ & & 0.653 \\
\hline Yes & 42 & $2.925(1.630-5.250)$ & & $0.860(0.445-1.662)$ & \\
\hline No & 81 & 1.0 & & 1.0 & \\
\hline HEF1 expression & & & 0.001 & & 0.028 \\
\hline Low & 60 & 1.0 & & 1.0 & \\
\hline High & 63 & $2.876(1.515-5.460)$ & & $2.212(1.091-4.484)$ & \\
\hline
\end{tabular}

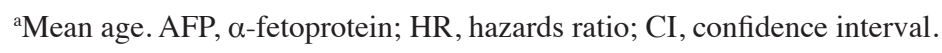


A

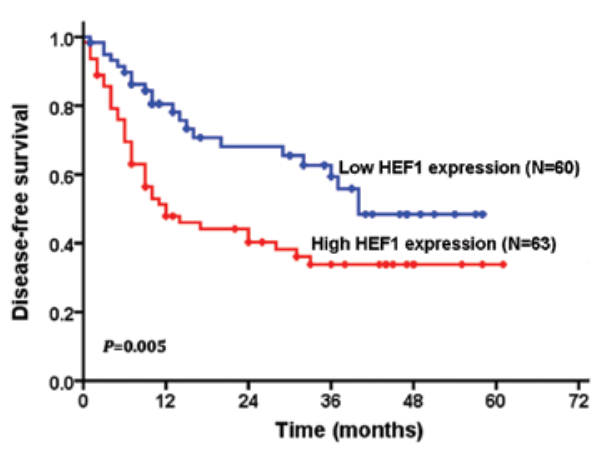

C

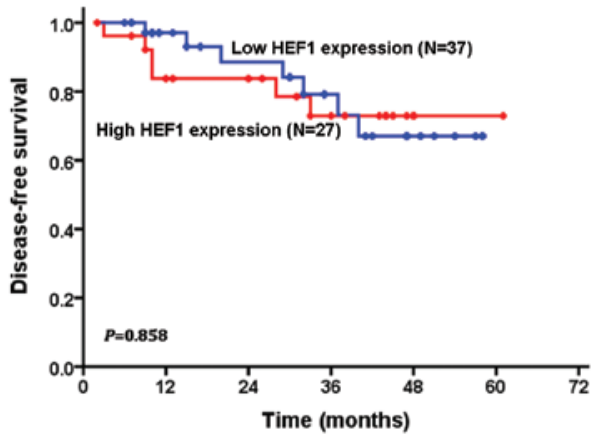

$\mathbf{E}$

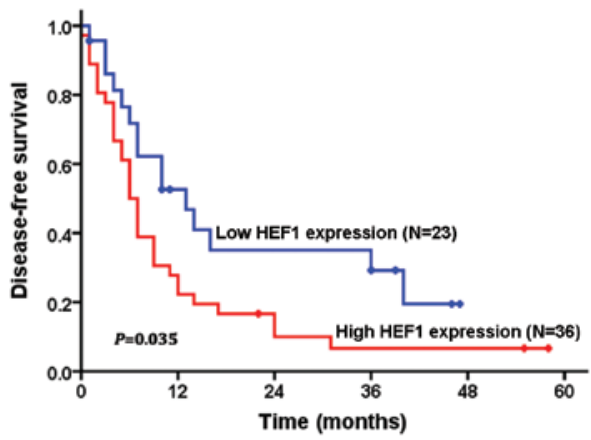

B
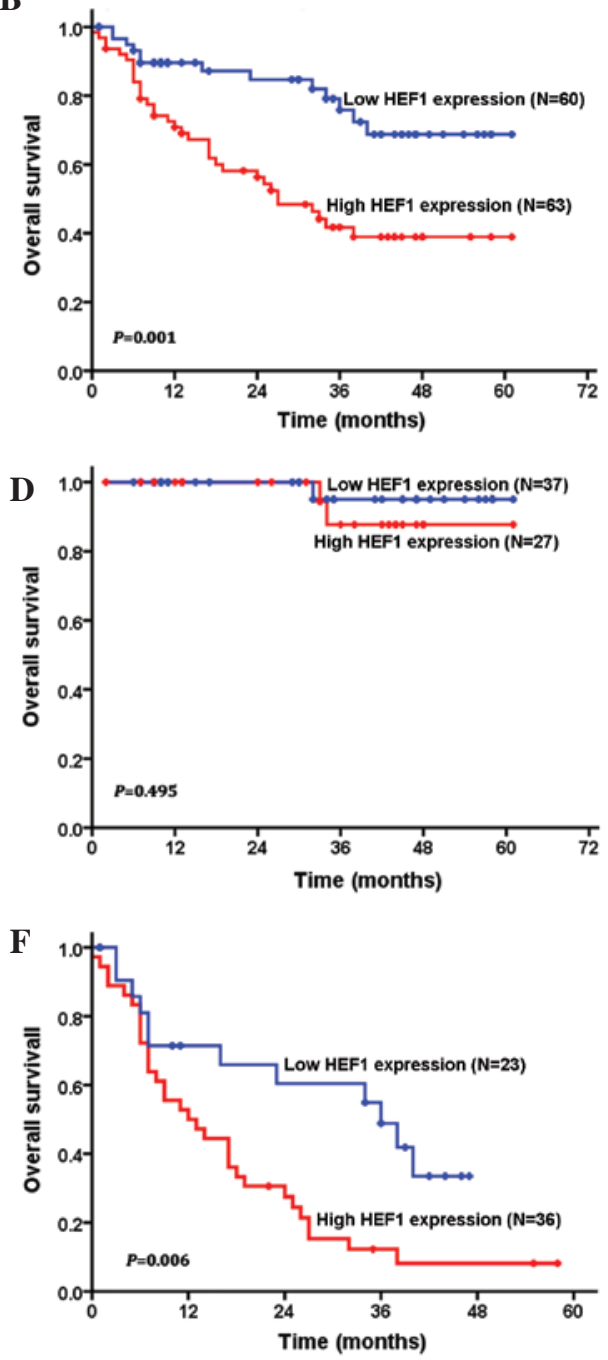

Figure 2. DFS and OS curves for the total and subsets of patients with HCC, according to their HEF1 expression status by Kaplan-Meier survival analysis. DFS and OS curves of patients with (A and B) low and high expression levels of HEF1, (C and D) early stage (I+II) HCC patients based on their HEF1 expression status and (E and F) advanced stages (III+IV) of HCC patients based on their HEF1 expression status. DFS, disease-free survival; HCC, hepatocellular carcinoma; OS, overall survival.

with primary tumors, indicating that it may serve a role in the initial invasion process from the primary site (25). Numerous possible mechanisms have been proposed in different cancer types $(11,26)$. McLaughlin et al $(27)$ reported that HEF1 expression is more frequently observed in invasive phenotypes of breast cancer cells and is crucial for the protease-dependent mesenchymal invasion process through the regulation of matrix metalloproteinase 14, a key enzyme in extracellular matrix degradation and tumor invasion. Other evidence includes the discovery of the association between HEF1 and Aurora A kinase (AURKA) in cancer cells. AURKA is an oncoprotein, which is tightly associated with decreased survival and tumor metastasis. Ice et al (28) showed that binding of HEF1 with AURKA is critical for Aurora stabilization and, therefore, protein level. A combination therapy with HEF1 RNA interference and AURKA inhibitors revealed significant effects on inhibiting growth and distant metastasis of xenografts of breast tumors in mice. Another line of evidence for the role of HEF1 in the growth of breast cancer cells is about cell surface-associated glycan structure. Iida et al (29) demonstrated that HEF1 in breast cancer cells enhances the expression of Chondroitin sulfate-E, which is a key progression and metastasis regulator in breast cancer. This provided a novel mechanism by which HEF1 promotes the malignant phenotypes of breast cancer cells. Consistently, in the present study, high expression of HEF1 was markedly associated with vascular invasion, TNM stages and unfavorable prognosis in HCC. However, the specific mechanism by which HEF1 enables HCC cells to acquire growth and metastasis advantages remains to be elucidated.

Staging of patients with $\mathrm{HCC}$ is critical for the prognosis prediction and selection of therapy. HCC is distinctive from other solid malignancies since its prognosis not only depends upon the tumor stage, but also on the liver function impairment, due to the accompanying cirrhosis. Individual specificity and treatment plans are also important in the prognosis of a particular patient (30). Therefore, a comprehensive and effective staging system for HCC must take traditional TNM stage, liver function parameters and various molecular markers, including VEGF, Ki67, p53, c-myc and E-adherin, into consideration (31). Nowadays, various staging systems for HCC, including the European systems, Barcelona Clinic Liver Cancer staging system, Chinese University Prognostic Index, 
Japan integrated Staging and the cancer of the liver Italian program, are working towards this goal. Japan integrated staging has recently added biomarkers (AFP, DCP, AFP-L3) into its evaluation system and extensive studies are focused on the discovery of novel biomarkers, including HEF1 (32,33). As shown in the present study, the expression of HEF1 correlated with tumor metastasis and can be used as an independent prognostic factor for $\mathrm{HCC}$ patients. It is anticipated that it can be used in combination with other critical parameters to assess prognosis and guide treatment.

In conclusion, the present study showed that increased HEF1 expression is markedly associated with advanced tumor stage, vascular invasion and poorer clinical outcomes of patients with HCC. In addition, HEF1 expression was revealed to be an independent prognostic factor for HCC patients, suggesting that it may serve as an effective biomarker for prognosis prediction. However, the detailed mechanisms by which HEF1 promotes tumor invasion and metastasis in HCC requires further studies.

\section{References}

1. Siegel RL, Miller KD and Jemal A: Cancer statistics, 2015. CA Cancer J Clin 65: 5-29, 2015

2. Wei KR, Yu X, Zheng RS, Peng XB, Zhang SW, Ji MF, Liang ZH, Ou ZX and Chen WQ: Incidence and mortality of liver cancer in China, 2010. Chin J Cancer 33: 388-394, 2014.

3. Fan JH, Wang JB, Jiang Y, Xiang W, Liang H, Wei WQ, Qiao YL and Boffetta P: Attributable causes of liver cancer mortality and incidence in China. Asian Pac J Cancer Prev 14: 7251-7256, 2013.

4. Kumar S, Tomooka Y and Noda M: Identification of a set of genes with developmentally down-regulated expression in the mouse brain. Biochem Biophys Res Commun 185: 1155-1161, 1992.

5. Feng Y, Wang Y, Wang Z, Fang Z, Li F, Gao Y, Liu H, Xiao T, Li F, Zhou Y, et al: The CRTC1-NEDD9 signaling axis mediates lung cancer progression caused by LKB1 loss. Cancer Res 72: 6502-6511, 2012 .

6. Guerrero MS, Parsons JT and Bouton AH: Cas and NEDD9 contribute to tumor progression through dynamic regulation of the cytoskeleton. Genes Cancer 3: 371-381, 2012

7. Han T, Yi XP, Liu B, Ke MJ and Li YX: MicroRNA-145 suppresses cell proliferation, invasion and migration in pancreatic cancer cells by targeting NEDD9. Mol Med Rep 11: 4115-4120, 2015.

8. Morimoto K, Tanaka T, Nitta Y, Ohnishi K, Kawashima H and Nakatani T: NEDD9 crucially regulates TGF- $\beta$-triggered epithelial-mesenchymal transition and cell invasion in prostate cancer cells: Involvement in cancer progressiveness. Prostate 74 901-910, 2014

9. Feng J, Zhao J, Xie H, Yin Y, Luo G, Zhang J, Feng Y and Li Z: Involvement of NEDD9 in the invasion and migration of gastric cancer. Tumour Biol 36: 3621-3628, 2015.

10. Jin Y, Li F, Zheng C, Wang Y, Fang Z, Guo C, Wang X, Liu H, Deng L, Li C, et al: NEDD9 promotes lung cancer metastasis through epithelial-mesenchymal transition. Int J Cancer 134 2294-2304, 2014.

11. Stajduhar E, Sedić M, Leniček T, Radulović P, Kerenji A, Krušlin B, Pavelić K and Kraljević Pavelić S: Expression of growth hormone receptor, plakoglobin and NEDD9 protein in association with tumour progression and metastasis in human breast cancer. Tumour Biol 35: 6425-6434, 2014

12. Xue YZ, Sheng YY, Liu ZL, Wei ZQ, Cao HY, Wu YM, Lu YF, Yu LH, Li JP and Li ZS: Expression of NEDD9 in pancreatic ductal adenocarcinoma and its clinical significance. Tumour Biol 34: 895-899, 2013.

13. Li P, Zhou H, Zhu X, Ma G, Liu C, Lin B and Mao W: High expression of NEDD9 predicts adverse outcomes of colorectal cancer patients. Int J Clin Exp Pathol 7: 2565-2570, 2014.

14. Kondo S, Iwata S, Yamada T, Inoue Y, Ichihara H, Kichikawa Y, Katayose T, Souta-Kuribara A, Yamazaki H, Hosono O, et al: Impact of the integrin signaling adaptor protein NEDD9 on prognosis and metastatic behavior of human lung cancer. Clin Cancer Res 18: 6326-6338, 2012.
15. Sasaki T, Iwata S, Okano HJ, Urasaki Y, Hamada J, Tanaka H, Dang NH, Okano H and Morimoto C: Nedd9 protein, a Cas-L homologue, is upregulated after transient global ischemia in rats: Possible involvement of Nedd9 in the differentiation of neurons after ischemia. Stroke 36: 2457-2462, 2005.

16. Guo W, Ren D, Chen X, Tu X, Huang S, Wang M, Song L, Zou X and Peng X: HEF1 promotes epithelial mesenchymal transition and bone invasion in prostate cancer under the regulation of microRNA-145. J Cell Biochem 114: 1606-1615, 2013.

17. Edmonson $\mathrm{H}$ and Steiner PE: Primary carcinoma of the liver: A study of 100 cases among 48,900 necropsies. Cancer 7, 462, 1954.

18. Sobin LH and Fleming ID: TNM classification of malignant tumors, fifth edition (1997). union internationale contre le cancer and the american joint committee on cancer. Cancer 80 : 1803-1804, 1997.

19. Cai MY, Zhang B, He WP, Yang GF, Rao HL, Rao ZY, Wu QL, Guan XY, Kung HF, Zeng YX and Xie D: Decreased expression of PinX1 protein is correlated with tumor development and is a new independent poor prognostic factor in ovarian carcinoma. Cancer Sci 101:1543-1549, 2010.

20. O'Neill GM, Seo S, Serebriiskii IG, Lessin SR and Golemis EA: A new central scaffold for metastasis: Parsing HEF1/Cas-L/NEDD9. Cancer Res 67: 8975-8979, 2007.

21. Zhang Q, Wang HJ, Zhang DH, Ru GQ, He XJ and Ma YY: High expression of HEF1 is associated with poor prognosis in urinary bladder carcinoma. Onco Targets Ther 7: 1319-1326, 2014.

22. Wang H, Mu X, Zhou S, Zhang J, Dai J, Tang L, Xiao L, Duan Z, Jia L and Chen S: NEDD9 overexpression is associated with the progression of and an unfavorable prognosis in epithelial ovarian cancer. Hum Pathol 45: 401-408, 2014.

23. Zhang SS, Wu LH, Liu Q, Chen KS and Zhang XF: Elevated expression of NEDD9 is associated with metastatic activity in gastric cancer. Onco Targets Ther 8: 633-640, 2015.

24. Xia D, Holla VR, Wang D, Menter DG and DuBois RN: HEF1 is a crucial mediator of the proliferative effects of prostaglandin $\mathrm{E}(2)$ on colon cancer cells. Cancer Res 70: 824-831, 2010

25. Izumchenko E, Singh MK, Plotnikova OV, Tikhmyanova N, Little JL, Serebriiskii IG, Seo S, Kurokawa M, Egleston BL, Klein-Szanto A, et al: NEDD9 promotes oncogenic signaling in mammary tumor development. Cancer Res 69: 7198-7206, 2009.

26. Chang JX, Gao F, Zhao GQ and Zhang GJ: Role of NEDD9 in invasion and metastasis of lung adenocarcinoma. Exp Ther Med 4: 795-800, 2012.

27. McLaughlin SL, Ice RJ, Rajulapati A, Kozyulina PY, Livengood RH, Kozyreva VK, Loskutov YV, Culp MV, Weed SA, Ivanov AV and Pugacheva EN: NEDD9 depletion leads to MMP14 inactivation by TIMP 2 and prevents invasion and metastasis. Mol Cancer Res 12: 69-81, 2014.

28. Ice RJ, McLaughlin SL, Livengood RH, Culp MV, Eddy ER, Ivanov AV and Pugacheva EN: NEDD9 depletion destabilizes Aurora A kinase and heightens the efficacy lof Aurora A inhibitors: Implications for treatment of metastatic solid tumors. Cancer Res 73: 3168-3180, 2013.

29. Iida J, Dorchak J, Clancy R, Slavik J, Ellsworth R, Katagiri Y, Pugacheva EN, van Kuppevelt TH, Mural RJ, Cutler ML and Shriver CD: Role for chondroitin sulfate glycosaminoglycan in NEDD9-mediated breast cancer cell growth. Exp Cell Res 330: 358-370, 2015.

30. Bruix J and Llovet JM: Prognostic prediction and treatment strategy in hepatocellular carcinoma. Hepatology 35: 519-524, 2002.

31. Witjes CD, van Aalten SM, Steyerberg EW, Borsboom GJ, de Man RA, Verhoef C and Ijzermans JN: Recently introduced biomarkers for screening of hepatocellular carcinoma: A systematic review and meta-analysis. Hepatol Int 7: 59-64, 2013.

32. Kitai S, Kudo M, Minami Y, Ueshima K, Chung H, Hagiwara S, Inoue T, Ishikawa E, Takahashi S, Asakuma Y, et al: A new prognostic staging system for hepatocellular carcinoma: Value of the biomarker combined Japan integrated staging score. Intervirology 51 (Suppl 1): S86-S94, 2008.

33. Nishikawa H, Kita R, Kimura T, Endo M, Ohara Y, Sakamoto A, Saito S, Nishijima N, Nasu A, Komekado H and Osaki Y: Proposal of the performance status combined Japan integrated staging system in hepatocellular carcinoma complicated with cirrhosis. Int J Oncol 46: 2371-2379, 2015. 